\title{
COnE)-(OES
}

CIÊNCIA E TECNOLOGIA

\section{E-COMMERCE NA HOTELARIA DE FORTALEZA-CEARÁ: IMPACTOS ECONÔMICOS E COMPETÊNCIAS PARA O EXERCÍCIO PROFISSIONAL}

\author{
Victor Hugo Santos de Castro ${ }^{1}$, Nathália Nadja Sales e Sousa ${ }^{1}$ \\ ${ }^{1}$ Instituto Federal de Educação, Ciência e Tecnologia do Ceará - IFCE \\ <vsantosdecastro@yahoo.com.br><nathnadja@hotmail.com> \\ DOI:<https://doi.org/10.21439/conexoes.v15i0.1252>
}

\begin{abstract}
Resumo. A internet é uma tecnologia que revolucionou o mundo, gerando oportunidades para o turismo e principalmente para o setor hoteleiro. Com o avanço da internet, surge o comércio eletrônico ou e-commerce, que consiste na atividade de vendas de bens e serviços através da internet. O objetivo geral desta pesquisa foi analisar os impactos do comércio eletrônico na venda dos produtos e serviços nos empreendimentos hoteleiros de Fortaleza-Ceará. Tratou-se de uma pesquisa de campo, do tipo exploratória, com abordagem quali-quantitativa, cujos dados foram coletados por meio de entrevistas semiestruturadas e questionários, analisados através de transcrição de falas e gráficos, respectivamente. Os participantes da pesquisa foram os gestores de dez meios de hospedagem e cinquenta acadêmicos do curso de hotelaria de uma instituição de ensino superior da localidade. Os resultados obtidos evidenciam que a hotelaria vem explorando o e-commerce como um diferencial competitivo para vender mais acomodações no mercado. Notou-se que as agências de viagem online são os canais mais utilizados atualmente. Numa outra perspectiva observou-se que os acadêmicos de hotelaria necessitam e desejam mais conhecimentos sobre a área, que é promissora.
\end{abstract}

Palavras-chaves: Competências Profissionais. E-commerce. Fortaleza-Ceará. Hotelaria.

\section{E-COMMERCE IN FORTALEZA-CEARÁ HOTELS: FUNCTIONING, MANAGEMENT PERSPECTIVES AND PROFESSIONAL DIFFERENTIAL}

\begin{abstract}
The internet is a technology that has revolutionized the world, generating opportunities for tourism and especially for the hotel sector. With the advancement of the Internet, e-commerce or e-commerce, which consists of the activity of sales of goods and services through the internet, is born. The overall objective of this research was to analyze the impacts of e-commerce on the sale of products and services in hotel developments in Fortaleza-Ceará. This was an exploratory field research with a qualitative-quantitative approach, whose data were collected through semi-structured interviews and questionnaires, analyzed through transcription of speeches and graphs, respectively. The research participants were the managers of ten lodging facilities and fifty academics of the hotel course of a local higher education institution. The results show that the hotel industry has been exploring e-commerce as a competitive advantage to sell more accommodation in the market. It was noted that online travel agencies are the most widely used channels today. In another perspective it was observed that hotel academics need and want more knowledge about the area, which is promising.
\end{abstract}

Keywords: Professional Skills. E-commerce. Fortaleza-Ceará. Hospitality.

\section{INTRODUÇÃO}

A informação flui facilmente e em alta velocidade pela rede mundial de computadores através da internet. Esta e o comércio eletrônico, mais do que tendências e modismos, estão tornando-se uma das maiores alternativas estratégicas para as empresas, sobretudo no âmbito do turismo e hotelaria.

A hotelaria tornou-se cada vez mais complexa, dinâmica e competitiva, necessitando assim, de um método prático para compras e divulgação dos produtos e serviços. Esta é uma realidade que provoca fortes mudanças e quem não se adaptar ao dinamismo das atividades e inovações, estará sujeito à grandes prejuízos.

O surgimento do comércio eletrônico, denominado e-commerce ${ }^{1}$ foi essencial para que as operações de vendas de hospedagem se tornassem automatizadas, com um melhor acesso as informações dos meios de hospedagem pelos clientes, proporcionando maior agilidade, menores custos e uma maior segurança na realização das vendas em tempo instantâneo, para quem está vendendo e para quem está comprando em qualquer lu-

\footnotetext{
${ }^{1}$ Vendas de bens e serviços através da internet.
} 
gar do mundo.

O setor comercial também conhecido como vendas é, na hotelaria, o lugar onde as atividades de negociação são coordenadas e realizadas. O cotidiano deste departamento é caracterizado por alterações constantes nas vendas e surgimento de novas propostas de intervenção para obtenção de melhores resultados.

Este é o setor responsável por manter as relações do meio de hospedagem com as operadoras de turismo, as agências de viagens, as On Line Travel Agencies (OTA's) ${ }^{2}$ empresas parceiras e até mesmo com cliente final. É também, o elo entre a diretoria e ações de operação como reservas e recepção, por exemplo. Além de ser o responsável pelas ações que visam captar os clientes e superar os concorrentes.

O profissional que atua no setor comercial de um meio de hospedagem, para uma atuação exitosa, deve ter o conhecimento das ferramentas de vendas Online, pois somente através destas, é possível inserir informações como tarifários, conteúdo de mídia, quantidades de apartamentos disponíveis para venda e promoções. Atualmente, a gestão comercial dos empreendimentos hoteleiros precisa ter colaboradores que compreendam o comércio Online e estejam preparados para atuar neste contexto.

O tema se justifica por ser uma tendência de mercado, inclusive no setor hoteleiro de Fortaleza-Ceará. Tendo em vista o exposto, foi elaborada a seguinte pergunta como ponto de partida da pesquisa: quais os impactos do e-commerce para a hotelaria de Fortaleza na perspectiva dos gestores e as competências necessárias para o exercício profissional no setor comercial?

O objetivo geral desta pesquisa foi analisar os impactos do comércio eletrônico na venda dos produtos e serviços hoteleiros nos meios de hospedagem de Fortaleza-Ceará e as competências necessárias para o exercício profissional no setor comercial. Os objetivos específicos foram: analisar os canais utilizados para potencializar o e-commerce nos meios de hospedagem; averiguar como os gestores adquiriram o conhecimento para atuar na área comercial; detectar se o e-commerce é um diferencial competitivo na perspectiva da gestão; identificar o conhecimento em e-commerce de graduandos do curso superior de tecnologia em hotelaria de uma instituição de ensino superior de Fortaleza.

Este estudo tem relevância para os profissionais e acadêmicos da área de turismo e hotelaria, uma vez que ressalta o e-commerce como uma estratégia econômica para a referida área, assim como as habilidades que o profissional deve ter para ter êxito no setor comercial. $\mathrm{O}$ estudo é importante ainda para os profissionais de

\footnotetext{
${ }^{2}$ OTA'S, em português, significa Agências de Viagens Online
}

áreas afins como: administração, economia e logística.

\section{FUNDAMENTAÇÃO}

\subsection{O Setor Hoteleiro}

Andrade e Brito (2000) declaram que o crescimento do turismo nas últimas décadas, em âmbito mundial, possibilitou o surgimento de novas categorias de meios de hospedagem, diferenciadas pela quantidade de serviços que ofertam ao hóspede. Ressalta-se que, neste contexto de concorrência acirrada, a qualidade no atendimento é um diferencial para a fidelização de clientes. Castelli (2000) afirma que não basta somente satisfazer as exigências dos clientes, mas é preciso fazer melhor que a concorrência.

De acordo com o artigo 23 da Lei $n^{\circ} 11.771$ de 17 de setembro de 2008, também denominada como Lei do Turismo, meios de hospedagem são:

\footnotetext{
Os empreendimentos ou estabelecimentos, independentemente de sua forma de constituição, destinados a prestar serviços de alojamento temporário, ofertados em unidades de frequência individual e de uso exclusivo do hóspede, bem como outros serviços necessários aos usuários, denominados de serviços de hospedagem, mediante adoção de instrumento contratual, tácito ou expresso, e cobrança de diária (BRASIL 2008).
}

A hotelaria tem como premissa básica, acolher os indivíduos que estão longe de suas residências e que necessitam de uma acomodação para pernoitar e que atenda suas necessidades. Lara (2001) afirma que qualquer pessoa que realiza um deslocamento do seu domicílio para um lugar diferente do habitual, independente do motivo, torna-se cliente do setor hoteleiro.

Assim, uma das opções para hospedagem dos visitantes é o hotel, este pode ser compreendido como um estabelecimento comercial que objetiva acomodar indivíduos, temporariamente. De acordo com Castelli (2003), o hotel é um empreendimento que tem a finalidade de ofertar alojamento temporário para seus clientes, mediante o pagamento de diárias.

Um hotel é um "estabelecimento com serviço de recepção, alojamento temporário, com ou sem alimentação, ofertados em unidades individuais e de uso exclusivo dos hóspedes, mediante cobrança de diária" (OMT) 2003, p. 6).

Beni (2003, p. 196) afirma que a hotelaria se diferencia de outros setores, principalmente pelo fato de que:

O hotel é uma empresa de prestação de serviços e diferencia-se completamente de outros estabelecimentos industriais e comerciais. Enquanto na indústria pode-se planejar o número certo de equipamentos, instalações e pessoal para um determinado tipo de produção, o mesmo 
não acontece com a hotelaria, que fica no aguardo dos clientes para pôr em funcionamento seu esquema operacional. O produto hoteleiro é estático. O consumidor deve ir até ele. Já as empresas industriais ou comerciais fazem chegar o produto até o cliente. Os custos do esquema operacional hoteleiros são fixos. A empresa hoteleira, quando comparada a outros tipos de empresa, é menos propensa à automação, pois o tratamento pessoal e o calor humano fazem parte essencial da prestação dos serviços hoteleiros.

Além de uma boa infraestrutura, e qualidade nos serviços prestados, como mencionado anteriormente, os meios de hospedagem necessitam que seus processos acompanhem os avanços da tecnologia, buscando as tendências do mercado para a obtenção de melhores resultados nas vendas do principal produto da hotelaria, a acomodação, que pode ser realizada através de sítios eletrônicos e outras plataformas virtuais.

\subsection{E-commerce como Estratégia de Venda na Ho- telaria}

A globalização possibilitou a expansão da tecnologia e um acesso mais rápido à informação, através da internet, considerada uma rede aberta e mundial de comunicação, que possibilita o compartilhamento de dados e informações, através de equipamentos eletrônicos, como computadores, tablets, smartphones e outros.

Cruz e Gândara (2003, p. 113) afirmam que "a internet tem como pontos fortes a velocidade, baixo custo de estabelecimento, mudanças rápidas, distribuição internacional, relações personalizadas, facilidade de busca e as interconexões do ciberespaço". A internet possibilita melhorias empresariais, no que tange à organização de processo e maximização das vendas, inclusive no âmbito hoteleiro, uma vez que antes de viajar, o turista pesquisa sobre o destino e também busca informações sobre o meio de hospedagem, a fim de verificar se este atende as suas necessidades, gerando assim maior segurança no momento da reserva (compra).

Portanto, estar presente na internet é um fundamental para a visibilidade do meio de hospedagem, e, por conseguinte, maior índice de vendas de unidades habitacionais, esta ação pode ser entendida como ecommerce ou comércio eletrônico. Este é entendido como qualquer exercício comercial realizado eletronicamente com aplicação de tecnologias de informação (GUIMARAES; BORGES, 2008). Laudon e Laudon (1999) afirmam que o e-commerce é caracterizado pela inserção da tecnologia da informação nos processos de compra e venda de produtos e serviços, automatizando assim, a comercialização.

Deitel, Deitel e Steinbuhler (2004) reconhecem que os sítios eletrônicos proporcionam aos viajantes a pos- sibilidade de encontrar em um único lugar, as principais informações que necessitam para escolher um produto ou serviço. Logo, os meios de hospedagem devem possuir sites atrativos para que o possível cliente, possa sentir-se atraído pelo empreendimento e concretizar a compra.

Inúmeros meios de hospedagem possuem acordos com OTA's, a saber: Expedia, Booking, Decolar, BestDay, uma vez que através destes canais é possível expandir o processo de vendas de apartamentos disponíveis. Nas OTA's, o cliente visualiza fotos dos meios de hospedagem, opiniões de outros usuários, compara preços, analisa a disponibilidade e serviços ofertados, verifica a localização e os atrativos turísticos próximos, dentre outros.

É de suma relevância salientar que o comércio eletrônico pode ser realizado em duas modalidades, a primeira entre empresas e clientes, também conhecida como business to costumer ou B2C e a segunda entre organizações, denominada business to business ou B2B (COSTA, 2012).

Segundo o E-commerce Brasi ${ }^{3}$, grupo atuante no mercado nacional, que promove todas as ações de inovação para as empresas que vendem Online, as facilidades desta tendência de mercado estão intrinsecamente relacionadas à rapidez e comodidade de comprar, sem realizar um deslocamento, possibilidade de verificar os preços, que tendem a ser mais vantajosos, já que nas vendas Online, considera-se a redução de alguns custos operacionais, possibilidade de frete gratuito.

Laudon e Laudon (1999) admitem que no processo de vendas Online também existem desvantagens, como: a falta de contato humano, direto, durante as transações, já que os processos são realizados por plataformas e equipamentos eletrônicos; aspectos relacionados à segurança Online, caracterizados por clientes que não confiam em disponibilizar seus dados pessoais, como informações do cartão de crédito, em sites.

Observa-se que o comércio eletrônico é uma tendência de mercado, na contemporaneidade, e que as organizações buscam desenvolvê-lo na perspectiva de elevar as vendas, oferecendo mais uma forma de aproximação do cliente com o produto ou serviço, garantindo também informações que farão a diferença na decisão final de compra.

\section{METODOLOGIA}

Quanto à metodologia, tratou-se de uma pesquisa de campo, do tipo exploratória, com uma abordagem

\footnotetext{
${ }^{3}$ E-commerce Brasil: maior portal brasileiro de e-commerce, contendo reportagens sobre o crescimento desta modalidade no mercado.
} 

PROFISSIONAL

quali-quantitativa. Os cenários da pesquisa foram: dez hotéis que correspondem aos mais bem avaliados da cidade no TripAdvisor ${ }^{4}$ todos afiliados à Associação Brasileira da Indústria Hoteleira do Ceará (ABIH-CE); e uma instituição de ensino superior, que oferta o curso de Tecnologia em Hotelaria, na cidade de Fortaleza-Ceará.

A amostra foi composta por 10 gestores de empreendimentos hoteleiros e 50 acadêmicos do curso superior de Tecnologia em Hotelaria. A coleta de dados, com os gestores dos hotéis, foi realizada através de entrevistas semiestruturadas, compostas por cinco perguntas, onde as mesmas foram agendadas com antecedência, considerando a disponibilidade dos entrevistados, e realizadas no próprio ambiente de trabalho dos mesmos. Já os discentes responderam a um questionário, contendo quatro questionamentos objetivos.

Quanto ao número de acadêmicos ativos na instituição de ensino superior participante desta pesquisa para o recorte amostral, foi detectado junto à coordenação do curso que as turmas do segundo, do terceiro, do quarto e do quinto semestre, possuíam um total de 69 alunos regularmente matriculados no período de aplicação da pesquisa, destes, 50 responderam à pesquisa, o que representou um quantitativo de $72,46 \%$ do universo de discentes.

Quanto aos critérios de exclusão, os alunos do primeiro e do último semestre não participaram da pesquisa, pois os discentes do semestre inicial ainda não detinham conhecimentos teóricos necessários para responder as questões. Já os concluintes, estavam em processo de produção do trabalho de conclusão de curso, comparecendo apenas para o processo de orientação.

Ressalta-se que o anonimato dos gestores, alunos e instituição de ensino foi garantido, por questões de privacidade. As entrevistas e os questionários foram aplicados nos meses de janeiro e fevereiro de 2017. Os dados obtidos através das entrevistas foram analisados através da transcrição de falas e as informações oriundas dos questionários foram organizadas por meio da elaboração de gráficos, através do Microsoft Excel.

\section{RESULTADOS E DISCUSSÕES}

A primeira questão da entrevista com os gestores versou sobre os impactos do e-commerce para a hotelaria na contemporaneidade, como resultado obteve-se que o comércio eletrônico é um meio muito importante e forte de conseguir atingir o objetivo de qualquer meio de hospedagem que é a venda das unidades habitacionais e os serviços que a envolvam, como pode ser observado nas falas a seguir.

\footnotetext{
${ }^{4}$ Sítio eletrônico de viagens que disponibiliza conteúdos associados ao turismo e hotelaria.
}

Um gestor comercial deve acompanhar e analisar as tendências e mudanças do mercado. O e-commerce cresce cada vez mais na hotelaria e trouxe um mercado de oportunidades. Hoje é uma ferramenta essencial para a sobrevivência em um setor tão competitivo, pois permite a colocação do seu produto a um alcance mundial em uma fração de segundos, gerando um aumento de vendas, consequentemente um aumento em sua receita e lucratividade (GESTOR 01, PESQUISA DIRETA, 2017).

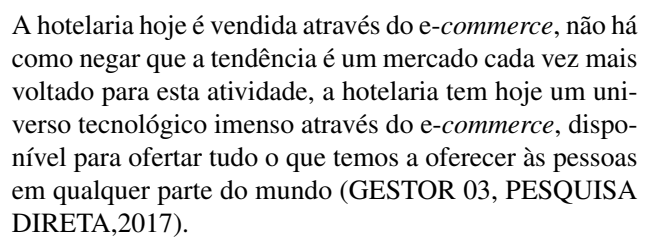

A hotelaria hoje é vendida através do e-commerce, não há como negar que a tendência é um mercado cada vez mais voltado para esta atividade, a hotelaria tem hoje um universo tecnológico imenso através do e-commerce, disponível para ofertar tudo o que temos a oferecer às pessoas em qualquer parte do mundo (GESTOR 03, PESQUISA DIRETA,2017).

Segundo a Organização Mundial do Turismo (2003), o turismo diferencia-se da maioria dos setores que utilizam o comércio eletrônico, em um elemento fundamental, o seu consumidor vai até o ponto de produção e lá percebe o produto. Dessa forma a hotelaria não precisa entregar produtos no mundo todo, apenas apresentá-los e disponibilizá-los para a compra.

A segunda pergunta foi sobre os canais (portais) fundamentais para a venda de produtos e serviços hoteleiros do empreendimento na perspectiva de gestão. Os resultados mostram que grandes OTA's são utilizadas em todos os hotéis entrevistados, além do próprio sítio eletrônico, como observado abaixo.

"Acredito que entre os canais que mais se destacam em vendas no mercado hoteleiro local atualmente, são as OTA's, como Booking, Expedia e Decolar" (GESTOR 7, PESQUISA, DIRETA, 2017). "Hoje a empresa CVC, tem representado mais de $50 \%$ das nossas vendas. Além disso, temos a Decolar como destaque, que pelo comissionamento diferenciado que pagamos, nos proporciona maior visibilidade dentro das buscas por hotéis em Fortaleza" (GESTOR 10, PESQUISA DIRETA, 2017).

Com essas informações é possível detectar que existe uma gama de portais que podem vender os hotéis e que cada um tem a sua negociação e condições próprias para pôr o empreendimento em evidência, e isto é de suma importância, visto que a cadeia da rede hoteleira já ultrapassa milhões.

$\mathrm{O}$ terceiro questionamento analisou a utilização do e-commerce como um diferencial competitivo no mercado hoteleiro. Os resultados apontam que é possível a obtenção de maior receita, uma vez que a amplitude de vendas é crescente, não existem barreiras para efetuar a reserva em um meio de hospedagem e que o posicionamento da empresa quanto à preferência do consumidor também é um diferencial significativo.

Sim, é fundamental estar presente na internet para ter 
uma visibilidade e vendas dos seus apartamentos, o alcance é muito maior, você divulga o seu produto para diversos países e para todos os tipos de clientes, gerando um aumento de suas vendas e receita. Hoje, um fator importante para as vendas é a sua reputação Online, como o hotel está sendo visto e comentado, pois a maioria das pessoas antes de realizar a compra na internet, verifica o que estão falando sobre aquele determinado empreendimento. Os portais de vendas Online, dão toda a visibilidade que precisamos e abre um leque de opções ao consumidor final, além de serem neles também onde podemos cuidar dessa reputação, verificando nossa posição nos rankings e respondendo aos comentários dos hóspedes, portanto, quem não estiver atento a este fator irá perder espaço no mercado, consequentemente perder capital (GESTOR 02, PESQUISA DIRETA, 2017).

De acordo com a Organização Mundial do Turismo (2003), o e-commerce conecta o fornecedor do produto turístico ao consumidor e também aos demais fornecedores, uma vez que através de plataformas eletrônicas é possível realizar transações financeiras de compras de bens ou serviços.

A quarta inquirição versou sobre a aquisição do conhecimento dos gestores, sobre o setor comercial, com foco no e-commerce. Os resultados apontam que o conhecimento foi adquirido no mercado, mesmo alguns tendo feito graduação na área de turismo e hotelaria, como pode ser observado abaixo.

\begin{abstract}
Sou graduada em Gestão de Turismo e Pós-graduada em Gestão Comercial, mas só tive acesso ao conhecimento sobre o e-commerce para a hotelaria no mercado de trabalho, no setor comercial da rede de hotéis em que trabalho. Acho muito válido e importante, que existam disciplinas direcionadas a esse assunto na graduação, pois o conhecimento é muito vasto e é ideal que o recém-formado tenha um conhecimento prévio do assunto (GESTORA 05, PESQUISA DIRETA, 2017).

Comecei na hotelaria, na cozinha. Fui crescendo, passando por vários setores até chegar à gerência. Todo meu conhecimento foi adquirido através do antigo gestor que me instruiu e pela vivência no dia a dia com gerentes de contas e coordenadores das Ota's que tenho parceria (GESTOR 4, PESQUISA DIRETA, 2017).
\end{abstract}

Foi percebido que muitos dos conhecimentos que envolvem o e-commerce são adquiridos no próprio mercado de trabalho, através dos treinamentos que são recebidos para atuação na área. Para Lara (2001) é importante buscar continuamente informações sobre elementos que possam modificar os processos no hotel, a fim de atender o público-alvo, com êxito.

A quinta e última pergunta da entrevista analisou as competências esperadas do profissional para atuar com o e-commerce. Os resultados apontam que um colaborador que irá desenvolver atividades no setor comercial, deve ter um conhecimento prévio sobre vendas e comércio eletrônico, ser ágil, organizado e dominar o idioma, inglês.
"Sempre procuro uma pessoa conectada com o mercado, o ideal é que o profissional da área seja dinâmico, flexível, organizado e com ideias inovadoras, que esteja pronto e disposto à todas as missões que a função exige" (GESTOR 8, PESQUISA DIRETA, 2017).

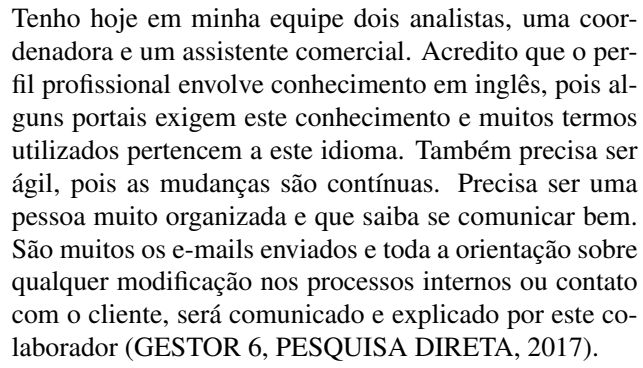

São muitas as informações contidas nos portais, e muitos termos encontram-se em inglês, como: allotments 5 e rates 6 O perfil ideal para o profissional da área existe, mas é muito raro encontrar pessoas capacitadas para este segmento, visto que a própria base, os gestores, em maioria, não chegam no ramo capacitados como deveriam.

A pesquisa aplicada acadêmicos de hotelaria, foi caracterizada por inquirições diretas com o intuito de saber o nível de conhecimento dos mesmos sobre o comércio eletrônico. A primeira questão versou sobre a ciência do termo e-commerce, uma vez que esta definição para a hotelaria é um fator antes de tudo, básico, na atualidade. Os resultados mostram que $54 \%$ da amostra, não sabe o que significa e-commerce, enquanto $46 \%$ já possui ciência (ver gráfico 1 .

Figura 1: Ciência sobre o e-commerce.

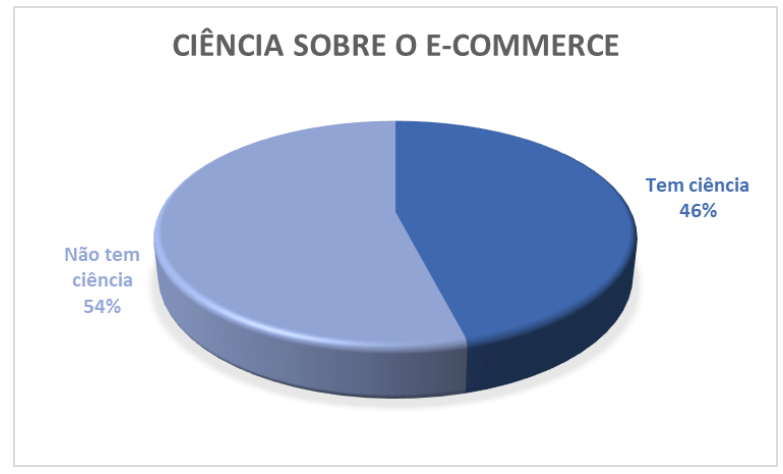

Este conceito apesar de fazer parte da área de formação e exposto de uma forma bem ampla no âmbito virtual, ainda não é conhecido por uma boa parte dos

\footnotetext{
${ }^{5}$ Allotments: em um meio de hospedagem, que consiste em bloquear, a favor de um agente ou operador, um número de quartos, para venda direta.

${ }^{6}$ Rates: Tarifas, preços, valor de venda.
} 

PROFISSIONAL

discentes do curso de hotelaria. Isso é um fator preocupante, pois não ter o conhecimento deste conceito tão básico, possibilita que profissionais de áreas afins ocupem o lugar de um hoteleiro no mercado. Ressaltase que o conteúdo de e-commerce é abordado dentro de outras disciplinas da área de hotelaria, esporadicamente, tornando-se incipiente para a atuação no mercado.

A segunda indagação analisou os conhecimentos sobre OTA's na hotelaria, os resultados demonstram que a maioria dos alunos, $78 \%$ da amostra desconhece esse termo, e $28 \%$ tem ciência do mesmo (ver gráfico 2).

Figura 2: Conhecimento sobre OTA's.

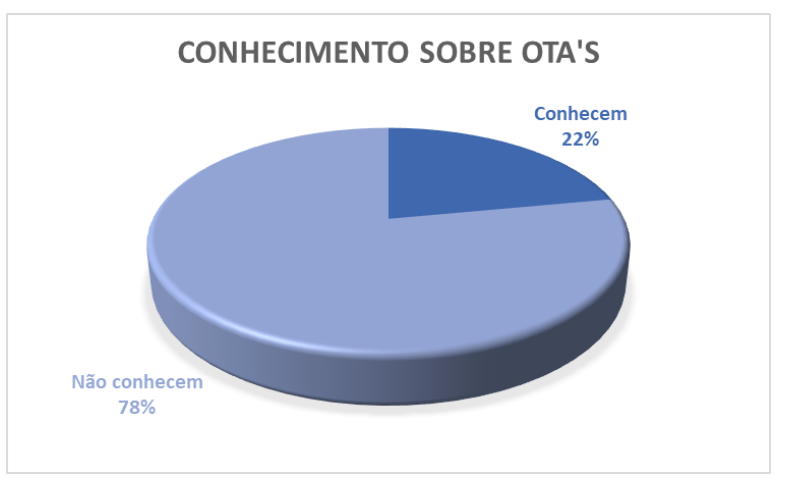

Compreende-se que as agências Online estão distantes dos assuntos tratados com os estudantes de hotelaria, o que pode significar uma barreira para uma possível atuação no e-commerce. Atualmente, setores como recepção, reservas, administrativo, até mesmo o financeiro de um hotel exige do profissional o conhecimento das OTA's, já que estas são exemplos de canais de ecommerce.

O terceiro questionamento versou sobre o domínio de motor de reservas. Os resultados apontam que $78 \%$ dos alunos não conhecem o que significa um motor de reservas e apenas $22 \%$ dominam a acepção (ver gráfico 3).

O domínio de algumas terminologias do cotidiano hoteleiro, sem dúvidas, irá dificultar a inserção do profissional no e-commerce. Tal assunto deveria ser abordado na disciplina de recepção e reservas, pois é a mais propícia para a abordagem. Motor de reserva é compreendido como o sítio eletrônico do próprio meio de hospedagem, para que o cliente possa visualizar a disponibilidade de acomodações, serviços disponíveis e assim, solicitar a reserva. Em suma, é uma forma de expor os produtos e serviços, efetuar o pagamento, concretizando assim, a venda.

A última indagação buscou identificar a necessidade de uma disciplina específica na área comercial no per-

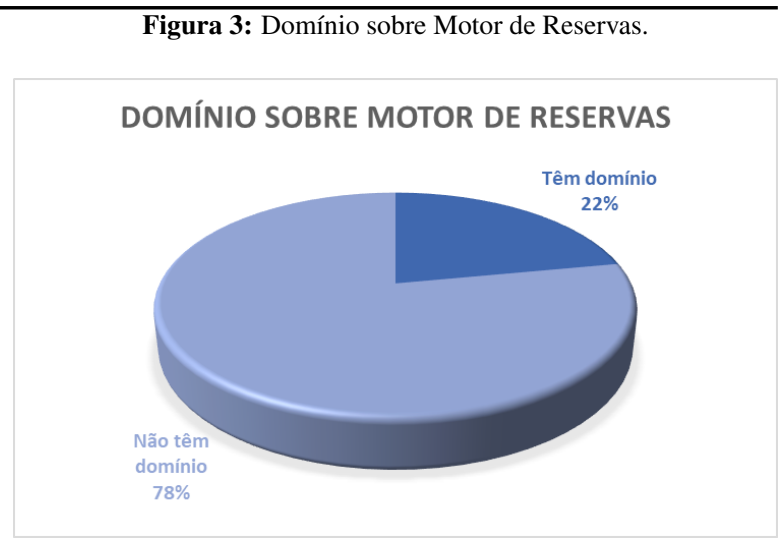

curso formativo no curso superior em questão. Os resultados apontam que $98 \%$ gostariam de ter uma disciplina apenas sobre o setor comercial e apenas $2 \%$ apontaram não ter interesse (ver gráfico 4 ).

Figura 4: Disciplina Específica sobre o setor Comercial na Graduação.

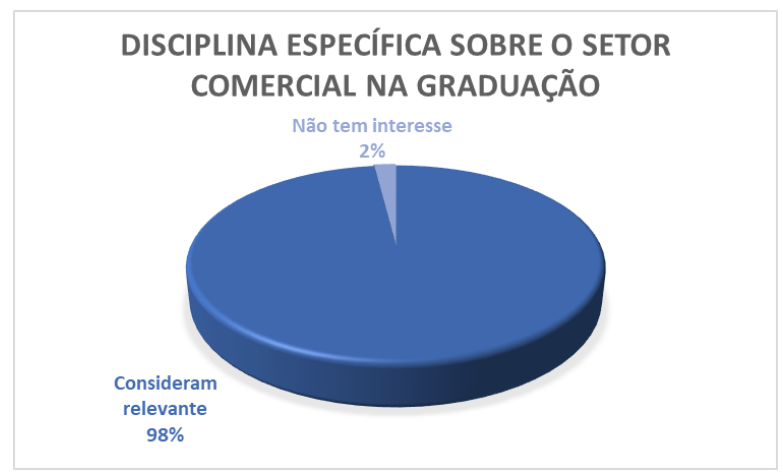

Constata-se que o comércio Online não é priorizado como conteúdo formativo essencial no referido curso de tecnologia em hotelaria e que também é pouco conhecido pela maioria dos estudantes de semestres diversos. Alguns discentes com visão de mercado e dinamismo, teriam uma grande probabilidade de se destacar com a abordagem da temática em sala de aula. Este conteúdo é, portanto, essencial para atender as necessidades do mercado hoteleiro, na atualidade.

\section{CONSIDERAÇÕES FINAIS}

Atentar que o e-commerce é a força motriz da atividade comercial na hotelaria atual é fundamental. Esta pesquisa teve como objetivo uma análise sobre os impactos do comércio eletrônico na venda dos produtos e serviços dos empreendimentos hoteleiros de FortalezaCeará, considerando as competências necessárias para o exercício profissional no setor comercial. 

PROFISSIONAL

O objetivo geral deste estudo, foi atingido, uma vez que se identificou que os impactos do comércio eletrônico na venda dos produtos e serviços hoteleiros nos meios de hospedagem de Fortaleza-Ceará são positivos, pois é possível aumentar as receitas, através da disponibilização dos produtos e serviços Online, possibilitando ao cliente acesso fácil às informações do empreendimento e comodidade na compra e que as competência profissionais esperadas para atuação neste setor são: conhecimento prévio sobre e-commerce, dinamismo, organização e domínio do idioma, inglês.

O objetivo específico referente à análise dos canais mais utilizados pela hotelaria para potencializar o ecommerce, foi logrado, uma vez que todos os meios de hospedagem confirmaram que vendem através das OTA's e que as mais importantes são: Booking, Expedia, Decolar e CVC. Identificou-se ainda, que além de serem as maiores fontes de receita para os hotéis, garantem grande visibilidade no mercado Online.

Já no que tange ao conhecimento dos gestores para atuação no âmbito comercial, observou-se que o mesmo foi obtido através da prática, apesar de terem formação na área de hotelaria e turismo. Os gestores afirmam ainda que o comércio eletrônico é, sem dúvidas, um diferencial competitivo na contemporaneidade, logrando assim, o segundo objetivo específico.

O último objetivo específico, referente ao conhecimento dos acadêmicos em hotelaria sobre o ecommerce, também foi atingido, pois foi verificou-se que os alunos ainda desconhecem terminologias importantes sobre o comércio eletrônico, e que anseiam uma formação específica para essa área na graduação. Dessa forma, é recomendada uma reforma na grade curricular do referido curso superior, para que o conteúdo sobre o setor comercial, possa ser inserido como uma disciplina.

Este estudo aponta outras possibilidades de pesquisa, para um maior aprofundamento da temática, uma vez que pesquisas nesta perspectiva ainda são incipientes, como por exemplo: as OTA's e sua representatividade econômica nos empreendimentos hoteleiros em outras cidades; o uso das mídias sociais como um canal de distribuição e divulgação dos produtos e serviços da hotelaria.

\section{REFERÊNCIAS}

ANDRADE, N.; BRITO, P. L. Hotel - Planejamento

e Projeto. 1. ed. São Paulo: SENAC, 2000.

BENI, M. C. Análise Estrutural do Turismo. 8. ed. São Paulo: SENAC, 2003.
BRASIL. Lei $\mathbf{n}^{\mathbf{0}} 11.771$ de 17 de setembro de 2008.

2008. Disponível em: <http://www.planalto.gov. br/ccivil_03/_ato2007-2010/2008/lei/111771.htm>

Acesso em: 04 mai. 2019.

CASTELLI, G. Excelência em Hotelaria. 1. ed. Rio de Janeiro: Qualitymark, 2000.

CASTELLI, G. Administração Hoteleira. 9. ed. Caxias do Sul: EDUCS, 2003.

COSTA, G. C. G. Negócios Eletrônicos: uma abordagem estratégica e gerencial. 1. ed. Curitiba: InteSaberes, 2012.

CRUZ, G.; GÂNDARA, J. M. O turismo, a hotelaria e as tecnologias digitais. Turismo-Visão e Ação, Universidade do Vale do Itajai-UNIVALI-Programa de Pos Graduação em Turismo ..., v. 5, n. 2, p. 107, 2003.

DEITEL, H. M.; DEITEL, P. J.; STEINBUHLER, K. E-business \& e-commerce para administradores. 1. ed. São Paulo: Pearson Educación, 2004.

GUIMARAES, A. S.; BORGES, M. T. E-Turismo: internet e negócios no turismo. 1. ed. São Paulo: Cengage Learning, 2008.

LARA, S. B. Marketing \& Vendas na Hotelaria. 1. ed. São Paulo: Futura, 2001.

LAUDON, K. C.; LAUDON, J. P. Sistemas de

Informação com internet. 1. ed. Rio de Janeiro: LCT, 1999.

OMT. E-business para Turismo. 1. ed. Porto alegre: Bookman, 2003. 